\title{
CONTRIBUIÇÃO AO CONHECIMENTO DA DISTRIBUIÇÃO ESPACIAL DOS ELEMENTOS Cu, Pb, Zn, Fe e Ba NO DISTRITO DO PERAU, PR*
}

A.P.Barbour ${ }^{1}$

A.B.Macedo ${ }^{1}$

A distribuição espacial de alguns elementos maiores e traços no distrito do Perau configura zoneamento horizontal e vertical no nível sulfetado.

$\mathrm{Pb}$ e $\mathrm{Ag}$ associados à galena, $\mathrm{Fe}$ contido na pirita e calcopirita, e $\mathrm{Au}$ associado à pirita mostram tendência, em maior ou menor intensidade, de aumento em direção ao provável centro da bacia de deposição, caracterizando um zoneamento horizontal (Fig. 1).

$\mathrm{Zn} \mathrm{e} \mathrm{SiO}_{2}$ comportam-se de maneira diversa, mostrando tendência de aumento de teor em direção à borda da bacia (Fig. 1).

O padrão de distribuição dos elementos Terras Raras ressalta tendência de enriquecimento em elementos leves, anomalia negativa do elemento Európio, e diminuição do conteúdo total de elementos Terras Raras com o afastamento do sítio mineralizado (Fig. 2).

O zoneamento vertical, embora ressaltado através de um menor número de elementos no nível sulfetado, foi também caracterizado através de elementos traços nas encaixantes no minério. B e Mg, elementos típicos de atividades pneumatolíticas/hidrotermais, apresentam valores que aumentam em direção ao nível sulfetado (Fig. 3). Fe constituindo pirita, disseminada na lapa do nível mineralizado, antecede a nucleação principal dos sulfetos de $\mathrm{Pb}, \mathrm{Zn}$ e $\mathrm{Cu}$ (Fig. 3).

$\mathrm{Pb}, \mathrm{Zn}, \mathrm{Cu}, \mathrm{Ag}$ e $\mathrm{Au}$ exigem ainda estudos quantitativos mais pormenorizados de modo a caracterizar o zoneamento vertical. Barita ocorre, à semelhança de outros distritos portadores de sulfetos de metais base, capeando ou localizada

*Financiado através do Projeto PADCT/FINEP/IG/USP 4286054500.

${ }^{1}$ Departamento de Geologia Econômica e Geofísica Aplicada, Instituto de Geociências/USP, São Paulo. 
estratigraficamente acima do horizonte sulfetado. Em direção à borda da bacia onde localizase o Perau SW, associam-se, no mesmo nível, barita e sulfetos de $\mathrm{Pb}, \mathrm{Zn}$ e Cu. Sulfetos fragmentados e milonitizados, clastos de pirita, e adelgaçamentos e espessamentos do nível sulfetado salientam uma tectônica ativa sin e pós-mineralização, sobrepondo fenômenos locais e regionais.

As características geologicas gerais da jazida, somadas ao fato de os elementos índices de mineralização apresentarem-se com teores mais altos nas rochas da capa e configurar-se a ausência de lixiviaçáo e/ou concentração anormal de alguns elementos típicos nas rochas da lapa, condicionam a gênese da jazida do Perau a um modelo exalativo distal em relação à fonte de mineralização. 


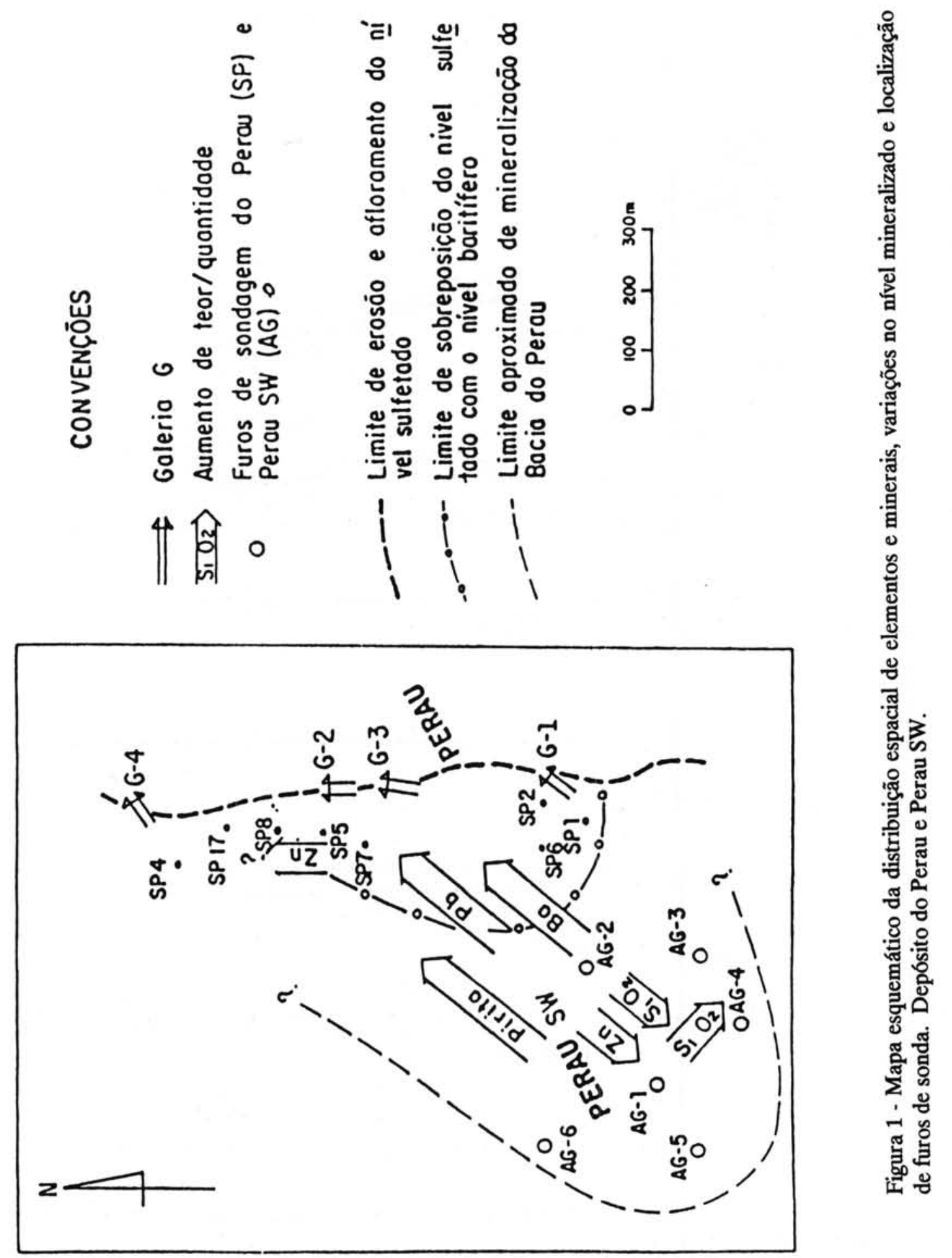




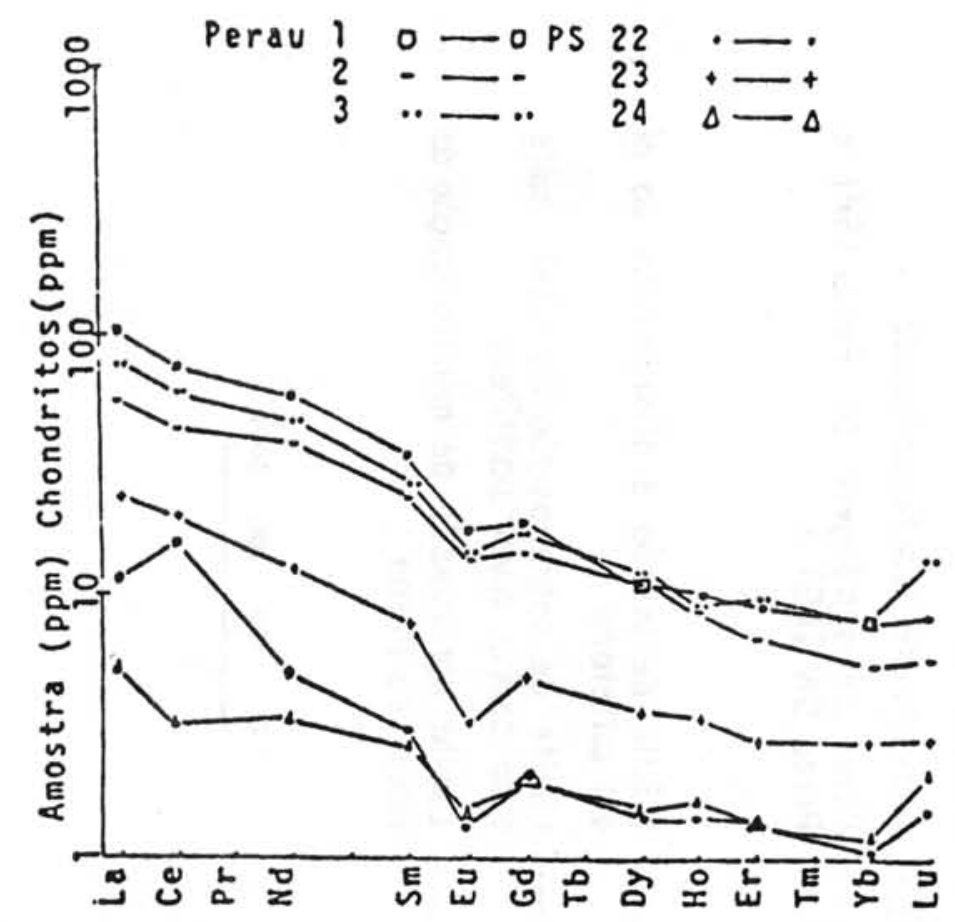

Figura 2 - Padrão de distribuição de elementos Terras Raras em formações ferriferas do Perau.

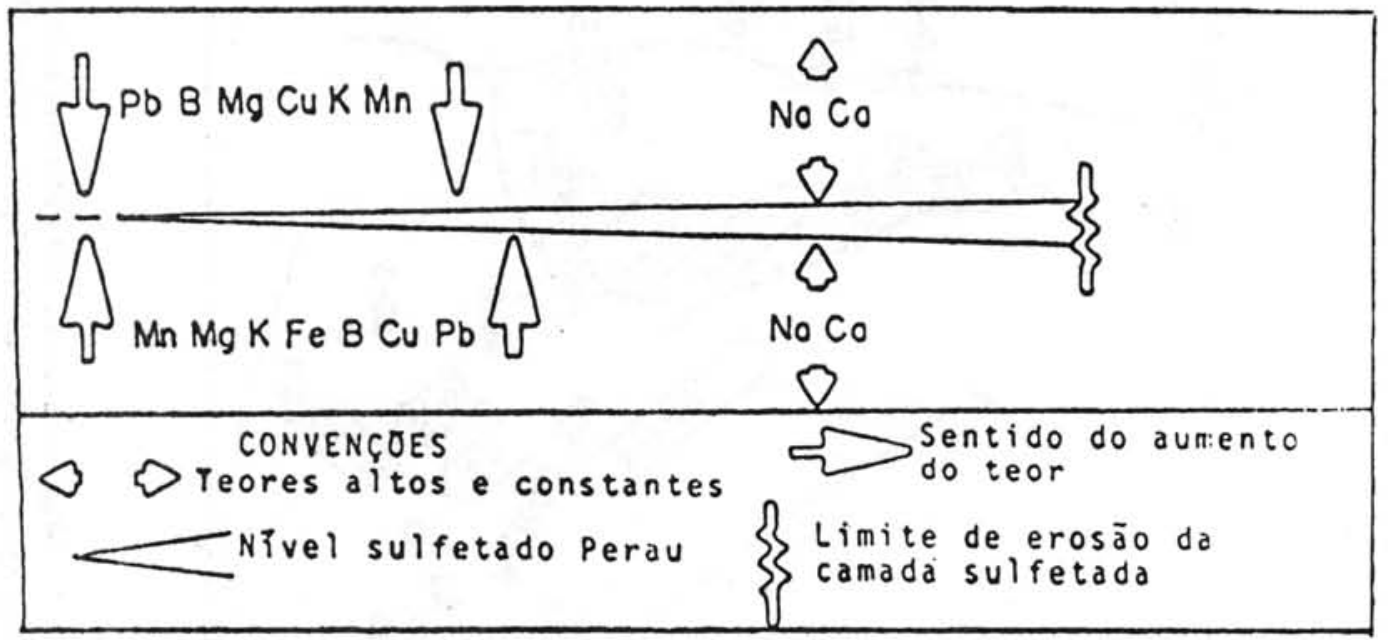

Figura 3 - Variação do teor dos elementos das rochas encaixantes em relação ao nível sulfetado da jazida do Perau. 